\title{
Correction
}

\section{Correction: Causes and Outcomes of Acute Liver Failure in China}

\section{The PLOS ONE Staff}

There are errors in Tables 1 and 2. The ">" symbol was removed while this article was being prepared for publication during the production process. The symbol was also removed in the text "HE grade ( $\mathrm{II}$ and $>$ II)" in the paragraphs preceding each table. Please see the correct tables below. 
Table 1. Baseline characteristics of patients with acute liver failure on admission and comparison of variables between patients who survived and died.

\begin{tabular}{|c|c|c|c|}
\hline Parameters & Patients who survived $(n=65)$ & Patients who died $(n=112)$ & $P$ value \\
\hline Sex (male/female) & $33 / 32$ & $49 / 63$ & 0.37 \\
\hline Age (years) & $40.0(31.0)$ & $46.0(31.5)$ & 0.03 \\
\hline Etiologies & & & 0.26 \\
\hline Drug (non-herb) toxicity & 18 & 29 & \\
\hline Herbs & 12 & 18 & \\
\hline Indeterminate cause & 13 & 39 & \\
\hline Viral causes & 10 & 10 & \\
\hline Other causes & 12 & 16 & \\
\hline Grade of HE & & & $<0.01$ \\
\hline$\leq \|$ & 57 & 31 & \\
\hline$>\| l$ & 8 & 81 & \\
\hline Days from onset of illness to the development of $\mathrm{HE}$ & $11(15)$ & $10(15)$ & 0.30 \\
\hline Serum ALT (U/L) & 796 (1817) & $756(1162)$ & 0.90 \\
\hline Serum AST (U/L) & $392.0(1244.5)$ & $534.0(824.0)$ & 0.43 \\
\hline Serum ALP (U/L) & $162(83)$ & $165(87)$ & 0.85 \\
\hline Serum TBil $(\mu \mathrm{mol} / \mathrm{L})$ & $326.35 \pm 161.32$ & $357.57 \pm 152.70$ & 0.76 \\
\hline Serum albumin ( $g / L)$ & $29(6)$ & $28(8)$ & 0.06 \\
\hline Serum cholinesterase $(\mathrm{U} / \mathrm{L})$ & 2964 (2045) & 2895 (1997) & 0.33 \\
\hline Serum LDH (U/L) & $264.0(164.0)$ & $366.5(486.0)$ & $<0.01$ \\
\hline Serum creatinine ( $\mu \mathrm{mol} / \mathrm{L})$ & $84.5(38.0)$ & $88.0(57.0)$ & 0.25 \\
\hline Serum urea nitrogen $(\mathrm{mmol} / \mathrm{L})$ & $4.00(4.25)$ & $3.9(5.3)$ & 0.48 \\
\hline Serum glucose (mmol/L) & $5.15(3.13)$ & $5.85(4.00)$ & 0.06 \\
\hline Serum $\mathrm{Na}^{+}(\mathrm{mmol} / \mathrm{L})$ & $137(6)$ & $135(8)$ & 0.08 \\
\hline Serum K $\mathrm{K}^{+}(\mathrm{mmol} / \mathrm{L})$ & $3.74 \pm 0.59$ & $3.86 \pm 0.70$ & 0.29 \\
\hline Serum $\mathrm{Cl}^{-}(\mathrm{mmol} / \mathrm{L})$ & $102.9(6.9)$ & $100.5(8.6)$ & 0.14 \\
\hline White blood cell count $\left(\times 10^{9}\right)$ & $8.35(5.42)$ & $10.45(8.61)$ & 0.11 \\
\hline Platelet count $\left(\times 10^{9}\right)$ & $122(106)$ & $87(102)$ & 0.01 \\
\hline Hemoglobin (g/L) & $116.5(34.0)$ & $118.7(36.5)$ & 0.37 \\
\hline PTA (\%) & $30.00(17.21)$ & $16.97(13.70)$ & $<0.01$ \\
\hline INR & $1.78(0.91)$ & $3.39(1.64)$ & $<0.01$ \\
\hline Arterial BLA ( $\mu \mathrm{mol} / \mathrm{L})$ & $70.50(28.15)$ & $153.50(62.00)$ & $<0.01$ \\
\hline Arterial blood lactate $(\mathrm{mmol} / \mathrm{L})$ & $2.75(2.25)$ & $3.40(5.05)$ & 0.42 \\
\hline Arterial blood pH & $7.47(0.08)$ & $7.48(0.07)$ & 0.63 \\
\hline
\end{tabular}

HE, hepatic encephalopathy; ALT, alanine aminotransferase; AST, aspartate aminotransferase; ALP, alkaline phosphatase; TBil, total bilirubin; LDH, lactate dehydrogenase; PTA, prothrombin activity; INR, international normalized ratio; BLA, blood ammonia.

doi:10.1371/journal.pone.0080991.t001

Table 2. A model for prediction of the death in acute liver failure using entry variables.

\begin{tabular}{llll}
\hline Parameters & Odds ratio & $\mathbf{9 5 \%}$ Cl for Odds ratio & $P$ value \\
\hline Age (years) & 1.064 & $1.015-1.115$ & 0.01 \\
Grade of $\mathrm{HE}(>\| \mathrm{l}$ vs. $\leq \mathrm{II})$ & 7.459 & $1.024-54.327$ & 0.04 \\
INR & 10.019 & $2.530-39.677$ & $<0.01$ \\
Arterial BLA $(\mu \mathrm{mol} / \mathrm{L})$ & 1.035 & $1.004-1.067$ & 0.02 \\
\hline
\end{tabular}

Somers'D 0.951; Goodman-Kruskal Gamma 0.951; Kendall's Tau-a 0.438; concordance index 0.976.

$\mathrm{HE}$, hepatic encephalopathy; INR, international normalized ratio; BLA, blood ammonia; CI, confidence interval.

doi:10.1371/journal.pone.0080991.t002 


\section{Reference}

1. Zhao P, Wang C, Liu W, Chen G, Liu X, et al. (2013) Causes and Outcomes of Acute Liver Failure in China. PLoS ONE 8(11): e80991. doi:10.1371/ journal.pone.0080991 